\title{
Amplitude, facility and accuracy of accommoda- tion in a primary school population
}

\section{VR Moodley*}

Discipline of Optometry, University of Kwa Zulu-Natal, Westville Campus, Private Bag X54001 Durban, 4000 South Africa

< moodleyvr@ukzn.ac.za>

Received 25 August 2008; revised version accepted 9 December 2008

\begin{abstract}
Vision screening at an early age in children is important as it can identify aspects in the visual system that may need to be managed to enable a child to function optimally at school. The National School Vision Screening Programme was discontinued in many provinces of South Africa, often due to a lack of financial resources or adequately trained personnel. This action has resulted in the majority of children not having a visual examination during their school career. In a few instances where vision screenings are performed, these are usually limited to visual acuity (VA) evaluation alone; an endeavour that may miss many significant visual problems. The purpose of this article is to highlight the need for vision screening to be conducted in schools and for the screening protocols to include the various accommodative tests. A retrospective analysis of the amplitudes of accommodation, accommodative facility and accuracy of accommodation findings from a primary school vision screening of 264 chil-
\end{abstract}

dren between 6 and 13 years was undertaken in this study. Data was captured and analysed with Microsoft Excel. The ages of the children ranged from 6 to 13 years with a mean of 9.38 years $(\mathrm{SD}=1.85)$. One hundred and thirty eight (52.3\%) were males and $126(47.7 \%)$ females. A significant number of the children failed the monocular accommodative amplitude tests (24\%), binocular accommodative amplitude test (26\%), the accommodative facility (30\%) and the MEM test (27\%). These results highlight the need for a more comprehensive vision screening exercise rather than VA alone as this approach would have missed more than a quarter of the children who had other visual problems that could impact on their ability to perform optimally at school.

Key words: Vision Screening, Primary school children, Accommodative anomalies, Accommodation amplitude, Accommodation facility, Accommodation lag.

\section{Introduction}

The National School Vision Screening Programme has, over the years, been discontinued in many provinces of South Africa, often due to a lack of financial resources or adequately trained personnel. Coupled with the general lack of eye care services in many parts of the country, especially the rural areas, the ces- sation of this programme has resulted in the majority of children not having a visual examination throughout their school career. In the few instances where there may be school vision screenings performed, these are usually limited to visual acuity (VA) evaluation alone. If VA alone is tested, a significant number of children with binocular vision anomalies will go 
undiagnosed as suggested by a study by Francisco et $a l^{1}$ who found $22.3 \%$ of a clinical children population with accommodative (9.4\%) or binocular dysfunction (12.9\%). A personal review by the researcher, of the tasks performed and the ergonomic setup in the classroom environment, also highlights the fact that good VA alone will not ensure optimal functioning within that context. Performing visual screening tests that only evaluate VA is both inadequate and misleading, in that passing the exercise leads both parents and teachers into believing that the child's visual system is functioning normally and should not be contributing to any difficulties experienced in the classroom. It may also suggest that there is no need for a complete eye examination. The visual system is thereafter not considered as a problem, even when the child displays poor reading ability such as losing his/her place when reading, fatigue, using a finger as a guide under the words, tardiness in copying from the board and displaying a general disinterest in any near task.

Anecdotal reports by optometrists indicate an increase in the number of distraught parents seeking assistance after having been informed that their child is performing badly at school, does not concentrate, is easily distracted, may have an attention deficit disorder (ADD), be dyslexic or have some other learning disability. They arrive at the optometrist's rooms with a huge file of reports from the various clinicians (medical practitioner, speech therapist, audiologist, occupational therapist and educational psychologist) that they have consulted. A comprehensive visual examination often reveals that the child has a visual anomaly even in the presence of normal VA.

One admits that there are instances where the child's visual problem is not easily detected by parents or teachers. However, serious concern arises when informed that the child had gone through a vision screening at school or a visual examination by an optometrist prior to these other consultations and were informed that all was well on the basis of VA assessments and a subjective refraction only. These parents may have been spared an enormous amount of stress and trouble if the optometrist had evaluated all the visual skills in addition to the VA and ocular health status. Some of the visual skills that must be assessed for children are accommodative skills, convergence ability, saccades, pursuits, vergence ability, visual perception, directionality and motor co-ordina- tion. Activities associated with the learning environment can become extremely frustrating for a child experiencing difficulties due to these visual anomalies. The grave consequences of an inadequate visual assessment is highlighted by Dzik ${ }^{2}$ who reports a high percentage of these visual problems being associated with children who are involved in the juvenile court system after having dropped out of school. Having observed the significant demands on the accommodative system in the classroom and noting the anecdotal reports by optometrists that evaluation of the accommodative system usually only covers the amplitude of accommodation, this article highlights the various accommodative demands that a child faces within the classroom environment and reviews the prevalence of some of the possible accommodative anomalies and their consequences.

The child's accommodative system begins its development at birth and is adult-like by 3-4 months of age $^{3,4}$ and this system plays a significant role when the child begins pre-school. Visual development of children should be monitored throughout the early years for any interruption to the normal development. Age-appropriate eye and vision evaluation should be incorporated into the scheduled health evaluation routine for children ${ }^{5,6}$. The classroom environment serves as the primary centre within which the majority of the learning occurs for the period of the day that the child is at school. Prior to conducting visual screening at schools, the author set out to observe the daily activities of a group of primary school children. This observation revealed tasks such as reading (sometimes for extended periods), drawing, writing and copying from the board. Accommodative functions were considered to feature prominently for most of these activities. The main accommodative demands involved in performing these tasks included amplitude of accommodation, accommodative facility and sustainability of accommodation.

In a study conducted by Borsting et $\mathrm{al}^{7}$ among 392 school-aged children, accommodative insufficiency was found to be a common anomaly. Also, children may have more than one accommodative anomaly, therefore exacerbating the difficulties experienced with tasks within the classroom setting. This was evident in Duam's ${ }^{8}$ review of the records of 96 patients with accommodative insufficiency, in which the author found that, in addition to reduced accommoda- 
tive amplitude for their ages, there was a reduction in the facility of accommodation and a smaller lag of accommodation.

There are various categories of anomalies of accommodation $^{9,} 10$ which may be found in children, and they differ in symptoms and require different management strategies. These include accommodative insufficiency, accommodative excess, accommodative infacility, ill-sustained accommodation, accommodative spasm, accommodation inaccuracy and increased latency. The symptoms typically reported by patients with accommodative dysfunctions usually include $\mathrm{e}^{9-11}$ the following: blurred near vision, blurred vision when changing the focus from one distance to another, fatigue or decreased reading time, loss of attention and concentration, frontal headaches or ocular pain and avoidance of near tasks.

The clinical parameters usually evaluated in the diagnosis of accommodative anomalies include ${ }^{9-11}$ amplitude of accommodation (monocular and binocular), lag or lead of accommodation by objective means with monocular estimate method (MEM) retinoscopy, accommodative facility (monocular and binocular), positive/ negative relative accommodation (PRA/NRA) values and determination of the accommodative convergence/ accommodation (AC/A) ratio.

\section{Accommodative Insufficiency}

Accommodative insufficiency is a condition where the child does not have the required amplitude of accommodation to be able to focus clearly on the object of regard. In the classroom, the child may find that when reading or writing, the words appear blurred and doubled ${ }^{7,10}$. This insufficiency of accommodative demand will result in the child experiencing general asthenopia which Ciuffreda ${ }^{12}$ identifies as the main symptom experienced with near work. Other common symptoms of accommodative insufficiency are eyestrain, headaches, reading problems, fatigue and sleepiness, loss of comprehension over time, movement of the print and a pulling sensation around the eyes $^{8,10,11}$. The causes of accommodative insufficiency, although most often functional, may also be due to an underlying organic condition such as thyroid conditions, diabetes, myasthenia gravis or tuberculosis or may also be a side effect of systemic medication or drugs such as marijuana, antihistamines or botulism ${ }^{11}$. It is therefore important for the clinician to conduct a detailed case history and thorough examination to rule out any non-functional cause/s of anomaly.

Accommodative insufficiency is diagnosed by performing the push-up test or with the use of negative lenses, both of which are performed monocularly to determine the absolute accommodative ability. The monocular measurement will eliminate the effect of convergence which is physiologically coupled with accommodation $^{13}$. Hofstetter's formula ${ }^{14}$

$(A=15-0.25$ age, where $A$ is amplitude of accommodation) can be used to determine the minimum expected amplitude of accommodation that the child should have. The lag of accommodation is also used to identify a possible accommodative insufficiency. If the practitioner requires more than $+0.75 \mathrm{D}$ to neutralize the movement of the retinoscopic reflex, then the patient must be investigated for an insufficient accommodation. Such a patient will also fail the monocular and binocular $\pm 2 \mathrm{D}$ facility test ${ }^{10}$.

\section{Accommodation Infacility}

Children with normal amplitudes of accommodation may display an accommodative infacility problem. Accommodation infacility is a condition where the child has difficulty changing focus between different working distances, such as near and distance. The common symptoms of patients having difficulty changing focus from one distance to another ${ }^{9-11}$ will, in the classroom situation, translate to vision taking long to clear when looking from the board to the book and vice versa. Children with this condition are often the last to complete a copying task in the classroom. This constant blur experienced when initially changing focus and the attempts to clear the target quickly can be the primary reason for the asthenopic symptoms usually experienced by these patients. The most common testing method for this condition is to ask the child to look at a target of 6/7.5 letters at his/her habitual working distance and report when the letters are clear with each flip of the $\pm 2 \mathrm{D}$ lenses. The number of cycles that the child is able to clear in a minute is recorded. Scheiman and Wick ${ }^{10}$ reported expected monocular accommodative facility values of 5.5 cycles per minute (cpm) for 6 year olds (SD $=2.5 \mathrm{cpm}), 6.5 \mathrm{cpm}$ for 7 year olds $(\mathrm{SD}=2.0 \mathrm{cpm})$ and $7.0 \mathrm{cpm}$ for $8-12$ year olds $(\mathrm{SD}=2.5 \mathrm{cpm})$. The expected values for binocular facilities for the same age groups are $3 \mathrm{cpm}, 3.5 \mathrm{cpm}$ and $5 \mathrm{cpm}$ respectively $(\mathrm{SD}=2.5)$. 


\section{Ill-Sustained Accommodation}

Ill-sustained accommodation is a condition where there is a failure to maintain accommodation for close work $^{9}$ as a result of fatigue. It differs from accommodative insufficiency in that, although the patient may have the required amount of accommodative amplitude to focus on the target, the target begins to blur after a few minutes due to the inability to sustain the accommodation response at the fixation plane. Clinically, patients with the condition report that vision blurs after reading for prolonged periods, often accompanied by ocular discomfort and tearing. When initially measured, they usually have normal amplitudes of accommodation and accommodative facility. However, it may be found that the child's response with both accommodative facility and amplitude testing decrease with time. Since the accommodation fatigues over time, Duane ${ }^{15}$ refers to ill-sustained accommodation as an early stage of accommodation insufficiency. Testing for ill-sustained accommodation involves performing the amplitude of accommodation and accommodative facility tests. However in order to establish whether the child can sustain the accommodative function requires that the facility test is conducted for at least 1-2 minutes and the amplitude test is also repeated a few times. If positive, performance with both these tests will deteriorate over time. The expected norms for both these tests apply over the time of the test.

\section{Accommodative Excess}

Accommodative excess is a condition whereby the child exerts more accommodation than the amount that is required for a given working distance over a prolonged period. The ability to relax the accommodation is reduced. The common symptom is blurred distance vision after a prolonged period of reading ${ }^{9-11}$. These patients also have a tendency to hold their reading material closer than normal. Scheiman ${ }^{10}$ lists headaches, eyestrain, sensitivity to light and blurred vision worse after reading or close work as some of the symptoms of accommodative excess. This condition is diagnosed by performing dynamic retinoscopy in the form of MEM retinoscopy. The patient with accommodative excess will repeatedly show a lead of accommodation (accept negative lenses for neutralization), fails with $+2 \mathrm{D}$ lenses on the facility test and have a reduced NRA finding ${ }^{10,11}$.

\section{Accommodation Inaccuracy}

In addition to providing information on the amplitude of accommodation, the accuracy of the accommodative response is determined by testing whether the patient has a lag or lead of accommodation. Monocular Estimate Method (MEM) retinoscopy is conducted to determine the accuracy of accommodation. An accommodative lag of $1 \mathrm{D}$ or greater is a cause for further investigation ${ }^{11}$. Patients with a high lag of accommodation are expected to find it difficult to sustain the accommodation at the fixation plane for long periods of time and experience fatigue and asthenopia whilst reading

It is evident that the case history plays a vital role in the differential diagnosis of the accommodative anomalies. During vision screening, it is important to include those accommodative tests that will at least pick up areas of concern to be investigated further during a comprehensive eye examination. A retrospective analysis of the amplitudes of accommodation, accommodative facility and accuracy of accommodation findings from a school vision screening was undertaken in this study and the results are presented in this article.

\section{Methodology}

Two primary schools in Durban, Kwa Zulu-Natal province were visited where vision screening was performed on the children. Convenience sampling was utilized for the selection of the schools and the children screened. All children that were available at the schools on the day of the screening were included in the exercise. The screening was done in a room provided by the school authority and was conducted by an optometrist and optometry students, with one individual assigned to conduct a particular test for the duration of the screening period. The amplitude of accommodation was measured monocularly and binocularly with the RAF rule, accommodative facility was measured binocularly with $+2 \mathrm{D}$ flippers for a period of one minute and the accuracy of accommodation was measured using the MEM retinoscopy method. Data was captured and analyzed using Microsoft Excel.

\section{Results}

Two hundred and sixty four children $(N=264)$ were screened and their ages ranged from six to thir- 
teen years with a mean of 9.38 years (SD 1.85). One hundred and thirty eight (52.3\%) were males and 126 (47.7\%) females. Sixty four (24\%) were Indians and 200 (76\%) were Africans. The age distributions of the children in relation to gender are shown in Figure 1.

\section{FIGURE 1: PROFILE OF SUBJECTS (N=264)}

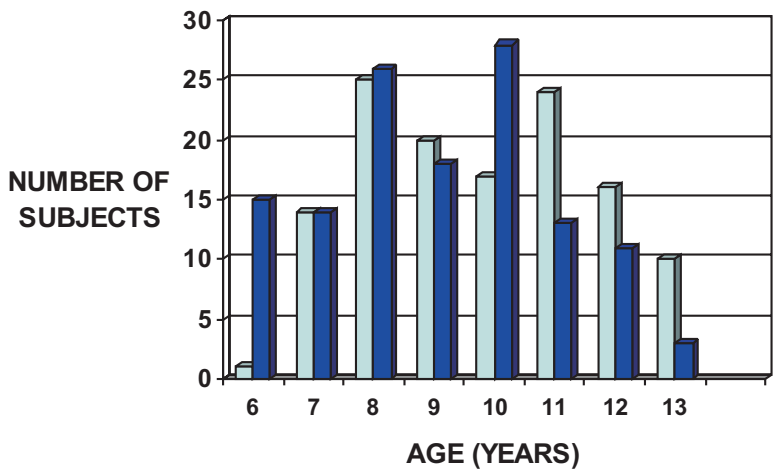

Figure 1: Shows the age and gender distribution of the children included in the study. The females were in the majority for the six, eight and ten year olds and the males were the majority for the other age groups.

\section{Amplitude of Accommodation}

Reduced monocular amplitude of accommodation was found in $24 \%$ of the children in both right and left eyes and reduced binocular amplitude of accommodation in $26 \%$ of the children when compared to the minimum expected values for their respective ages according to Hofstetter ${ }^{14}$. The range, mean and standard deviations of the amplitude of accommodation (OD, OS, OU) in relation to age and pass and failure rates are shown in Table 1. Except for the 13 year olds, who had the smallest sample size, the maximum amplitudes were 20.0 D for each age group, but the minimum amplitudes ranged from $7.0 \mathrm{D}$ to $10 \mathrm{D}$.

\section{Accommodation Facility}

The overall prevalence of binocular accommodation infacility was 30\% amongst all the children screened. The percentage of children that passed or failed the accommodative facility test in each age group is shown in Figure 2. The 10 year olds had the highest failure rate (40\%) and the 6 year olds the least (13\%). Table 2 shows the range of facility, mean and standard deviation of accommodative facility in the study. The mean accommodative facility for the group was $5.3 \mathrm{cpm}$.
Table 1: shows the minimum, maximum and mean amplitudes as well as the percentage of children who passed or failed the amplitude test for the right eye, left eye and binocularly.

\begin{tabular}{|c|c|c|c|c|c|c|c|}
\hline \multicolumn{8}{|c|}{ Amplitudes of Accommodation } \\
\hline \multirow[t]{2}{*}{$\begin{array}{l}\text { Age } \\
\text { (yrs) }\end{array}$} & \multirow[t]{2}{*}{ Eye } & \multicolumn{4}{|c|}{ Amplitude (D) } & \multicolumn{2}{|c|}{$\begin{array}{l}\text { Performance } \\
\text { rate }(\%)\end{array}$} \\
\hline & & Min & Max & Mean & SD & $\%$ Pass & \% Fail \\
\hline \multirow[t]{3}{*}{6} & $\mathrm{R}$ & 9 & 20 & 16.7 & 4.19 & 73 & 27 \\
\hline & $\mathrm{L}$ & 9 & 20 & 16.7 & 4.29 & 73 & 27 \\
\hline & $\mathrm{OU}$ & 10 & 20 & 17.1 & 4.19 & 73 & 27 \\
\hline \multirow[t]{3}{*}{7} & $\mathrm{R}$ & 8 & 20 & 16.3 & 3.10 & 79.6 & 21.4 \\
\hline & $\mathrm{L}$ & 7 & 20 & 16.4 & 3.17 & 75 & 25 \\
\hline & $\mathrm{OU}$ & 8 & 20 & 16.1 & 3.08 & 75 & 25 \\
\hline \multirow[t]{3}{*}{8} & $\mathrm{R}$ & 8.5 & 20 & 15.7 & 3.02 & 80.4 & 19.6 \\
\hline & $\mathrm{L}$ & 8.5 & 20 & 15.7 & 2.99 & 80.4 & 19.6 \\
\hline & $\mathrm{OU}$ & 8 & 20 & 15.8 & 3.00 & 80.4 & 19.6 \\
\hline \multirow[t]{3}{*}{9} & $\mathrm{R}$ & 7.5 & 20 & 15.3 & 3.60 & 68.8 & 31.2 \\
\hline & $\mathrm{L}$ & 7.5 & 20 & 15.2 & 3.69 & 70.8 & 29.2 \\
\hline & OU & 7.5 & 20 & 15.4 & 3.62 & 70.8 & 29.2 \\
\hline \multirow[t]{3}{*}{10} & $\mathrm{R}$ & 8 & 20 & 15.0 & 4.05 & 73.3 & 26.7 \\
\hline & $\mathrm{L}$ & 8 & 20 & 14.9 & 3.94 & 73.3 & 26.7 \\
\hline & $\mathrm{OU}$ & 8 & 20 & 14.9 & 4.10 & 73.3 & 26.7 \\
\hline \multirow[t]{3}{*}{11} & $\mathrm{R}$ & 6 & 20 & 14.9 & 3.65 & 70.3 & 29.7 \\
\hline & $\mathrm{L}$ & 7 & 20 & 14.8 & 3.69 & 70.3 & 29.7 \\
\hline & OU & 6 & 20 & 14.9 & 3.85 & 67.6 & 32.4 \\
\hline \multirow[t]{3}{*}{12} & $\mathrm{R}$ & 8 & 20 & 14.4 & 3.73 & 81.5 & 18.5 \\
\hline & $\mathrm{L}$ & 7 & 20 & 14.3 & 3.67 & 77.8 & 22.2 \\
\hline & OU & 6 & 20 & 14.4 & 3.78 & 74.1 & 25.9 \\
\hline \multirow[t]{3}{*}{13} & $\mathrm{R}$ & 8 & 17 & 13.8 & 3.05 & 76.9 & 23.1 \\
\hline & $\mathrm{L}$ & 10 & 17 & 13.9 & 2.47 & 84.6 & 15.4 \\
\hline & $\mathrm{OU}$ & 10 & 17 & 13.9 & 3.84 & 76.9 & 23.1 \\
\hline
\end{tabular}

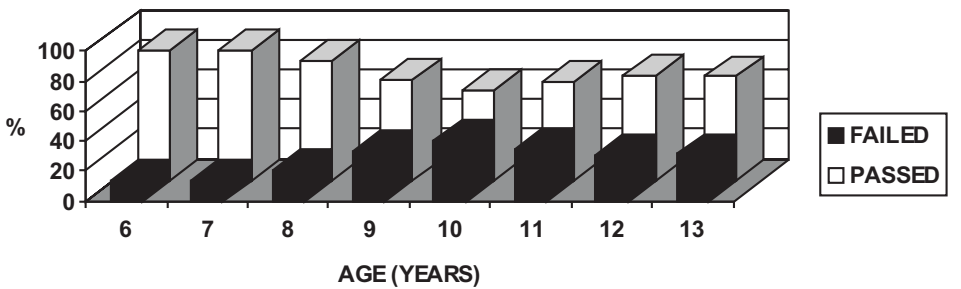

Figure 2: Shows the percentage of subjects that passed and failed the accommodative facility test. 


\section{Accommodation Accuracy}

The MEM retinoscopy values ranged from -0.50 $\mathrm{D}$ to $+1.50 \mathrm{D}$ with a mean of $+0.49 \mathrm{D}$ (SD 0.06 ) for all the children screened (Table 2). Twenty percent of the 7 year olds had abnormal MEM findings whilst only $7 \%$ of the 13 year olds failed the test. The overall failure rate in this test was $27 \%$ of the group and distributions of failure rate among each age group are shown in Figure 3.

Table 2: Shows the mean, ranges and standard deviations of the accommodation facility and accuracy findings.

BINOCULAR ACCOMMODATIVE FACILITY AND ACCURACY VALUES

\begin{tabular}{|l|l|l|c|c|c|c|}
\hline \multirow{2}{*}{$\begin{array}{l}\text { Age } \\
\text { (yrs) }\end{array}$} & \multicolumn{2}{|c|}{ FACILITY (cpm) } & \multicolumn{3}{c|}{ MEM (D) } \\
\cline { 2 - 7 } & Range & Mean & SD & Range & Mean & SD \\
\hline 6 & $2-8$ & 4.9 & 1.45 & $-0.25-1.25$ & 0.45 & 0.40 \\
\hline 7 & $1-7$ & 5.2 & 1.52 & $-0.50-1.25$ & 0.51 & 0.43 \\
\hline 8 & $2-7$ & 5.5 & 1.29 & $-0.25-1.00$ & 0.43 & 0.37 \\
\hline 9 & $2-7$ & 5.4 & 1.61 & $-0.25-1.50$ & 0.58 & 0.45 \\
\hline 10 & $1-8$ & 5.1 & 1.57 & $-0.25-1.25$ & 0.48 & 0.45 \\
\hline 11 & $1-7$ & 5.4 & 1.53 & $-0.25-1.50$ & 0.58 & 0.45 \\
\hline 12 & $2-7$ & 5.5 & 1.45 & $-0.25-1.50$ & 0.53 & 0.45 \\
\hline 13 & $3-7$ & 5.6 & 1.12 & $-0.25-1.25$ & 0.39 & 0.36 \\
\hline
\end{tabular}

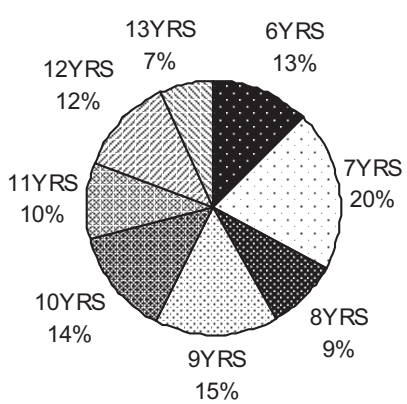

\begin{tabular}{|c|}
\hline @6YRS \\
\hline$\square 7 Y R S$ \\
\hline : 8YRS \\
\hline 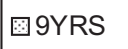 \\
\hline 图 10YRS \\
\hline 图11YRS \\
\hline O12YRS \\
\hline 13YRS \\
\hline
\end{tabular}

Figure 3: Shows the percentage of children who had reduced lag of accommodation in each age group. The highest percentage was among the 7 year olds.

\section{Discussion}

The Bill of Rights contained in the Constitution of the Republic of South Africa ${ }^{16}$, (Act 108 of 1996), states that everyone has the right to a basic education. (Television channels and various other community media highlight the importance of education during the early childhood years.) The new democratic dispensation aims to ensure that this right is attained, ir- respective of whether a child is rich or poor. Resources are being allocated by the national government in South Africa to improve the educational facilities in all schools. However, if educational facilities are provided, but there are visual and other sensory abnormalities present, the child will not benefit maximally from these new facilities. It is therefore important that the sensory organs (ear and eyes) which are important for accessing information during the learning process are constantly evaluated for every school child. Ayed et $\mathrm{al}^{17}$ showed a significant association between all types of refractive errors and academic failure in children from poor areas. They concluded that the ability of a child to participate in the educational experience is at least partially dependent on good vision. Their conclusion is corroborated by Gruning ${ }^{18}$ who reported that vision problems may not be the direct cause of learning disorders, but they can interfere with a child's ability to perform to his potential. As observed by the author prior to embarking on this study; in the classroom setting various accommodative functions play a major role in the daily activities of the child and the ability to perform these accommodative functions allows the child to engage in the learning tasks more efficiently.

This study showed that $26 \%$ of the subjects screened failed the binocular accommodative amplitude test, $30 \%$ the accommodative facility and $27 \%$ the lag of accommodation tests. Of the 264 children screened, only 26 (9.8 \%) failed the distance VA test and 34 (12.9\%) the near VA test. Also, among those who had deficient binocular functions, $89 \%$ had good VA. These results highlight the fact that screening of VA alone would have missed more than a quarter of the children who had other visual problems such as a binocular anomaly that could impact on their ability to perform optimally at school.

The highest percentages of failures for the monocular and binocular amplitudes were in the 9-11 age group. This is at variance with the findings of Marran et $a l^{13}$ who found a prevalence of $4.7 \%$ for accommodative insufficiency in school children in grade four to six. The prevalence is lower than that found in this study which involved a wider range of children from grades one to seven. The difference may be attributed to the larger variation in the age group. Another possible reason for the difference may be the influence of possible hyperopic refractive errors, shown to have a 
high prevalence amongst Black children by Mabaso et $a l^{19}$ who in their study involving 388 Black primary school children in South Africa found, of the total sample, 566 (72.9\%) eyes had hyperopia and only 19 (2.5\%) had myopia with 191 (24.6\%) having emmetropia. The greater occurrence of hyperopia, as compared to other refractive conditions, found in their study is similar to the findings reported by other authors ${ }^{20-22}$. Children with uncorrected hyperopia will need to use the available accommodation to overcome the hyperopia and when tested, manifest a reduced accommodative ability. This reduction in accommodative ability will cause the reading material to appear blurred and impact negatively on all reading and writing tasks in school. As these tasks are central to the child's learning, the academic performance will be negatively affected. It is therefore important that the refractive errors and binocular dysfunctions of the children are identified and properly managed where they occur.

Of all the tests performed in this study, the failure rate in the accommodative facility test was the highest $(30 \%)$, This agrees with the findings of Daum ${ }^{8}$, who found insufficiency and infacility as the most frequent forms of dysfunction. The high infacility rate could be due to the fact that children with poor abilities in any of the other accommodative functions (accommodative insufficiency, ill-sustained accommodation, accommodation excess) also display poor abilities in the accommodative facilities ${ }^{10}$. The mean accommodative facility on the binocular $\pm 2 \mathrm{D}$ flip test was 5.3 $+1.46 \mathrm{cpm}$, having a range which lies in between that found by Jackson and $\operatorname{Goss}^{23}(5.0 \pm 2.7 \mathrm{cpm})$ and Scheiman et $a l^{24}$ (3.83 $\left.\pm 2.5 \mathrm{cpm}\right)$. The differences may be attributed to the slight variations in the subject's age groups and the time necessary for saying "clear" as previously suggested by Kedzia et al ${ }^{25}$.

This large number of children who failed the facility test would have difficulty with changing their focus from one distance to another accompanied by intermittent blurred vision. This is a cause for concern as the inability to perform this task effectively will slow the child down when copying information from the board to the notebook in the classroom. When the diagnosis is confirmed, the accommodation infacility can be treated by the optometrist, who is a primary care practitioner that can administer and monitor the accommodation facility therapy to ensure that the child is able to change his/her focus easily within the classroom setting.

The mean MEM finding was $+0.49 \mathrm{D}(\mathrm{SD} \pm 0.06)$ which falls within the expected value ${ }^{10}$. However, twenty seven percent of the children had either a abnormal lag or a lead of accommodation which may warrant clinical management should such findings be subsequently confirmed through a comprehensive visual examination. In these instances, the vergence system must also be evaluated to ensure that any increased lag or an accommodative lead is not an attempt to compensate for a convergence excess or insufficiency problem by using the accommodation-convergence relationship. This highlights the need for the child who fails the MEM retinoscopy test during vision screening to undergo a comprehensive binocular vision evaluation to differentially diagnose the vergence or accommodative anomalies.

Testing of 1634 children ${ }^{26}$ using the New York State Vision Screening Battery (which probes oculomotor, binocular, accommodative, and visual perceptual functions) revealed a failure rate of 53\%. Also, a study of a clinical paediatric population by Scheiman et $a l^{27}$ found that other than refractive anomalies, the most prevalent conditions in the clinical paediatric population were binocular and accommodative disorders. The present study revealed a prevalence of accommodative anomalies ranging from $26 \%$ to $30 \%$. These findings serve to justify the need for vision screening to be conducted in all school children and for the screening to include binocular vision tests as part of the battery of tests performed. Optometrists also have to ensure that they include the evaluation of all the accommodative functions in their battery of tests conducted on children. The treatment of accommodative anomalies generally involve plus lenses or orthoptic therapy, ${ }^{8,28,29}$ which can easily be administered and monitored by optometrists. It is suggested that studies be conducted to determine whether the current norms used for accommodative tests effectively apply for African children.

\section{Conclusion}

Accommodative anomalies are important in the learning process of the child and the present study revealed that more than a quarter of the children tested had some form of accommodative anomaly that will negatively impact the functioning in the classroom. 
This suggests the need for regular comprehensive vision screening for primary school children.

\section{Recommendations}

Noting the importance of having an optimally functioning visual system in learning and based on the findings of this study, the following recommendations are made:

i. To achieve the aim of affording every child education, all attempts should be made by the relevant professions to ensure that the learning experience, during the early years, are maximized and all potential barriers to learning eliminated.

ii. Noting the importance of vision in learning, the South African government should reintroduce school vision screening in primary schools in all provinces and ensure that those conducting the vision screening are adequately trained to be able to detect and refer children with any type of visual anomaly that has the potential of hindering the learning of the child.

iii. Optometrists, as primary care providers of eye health and visual function, must also ensure that they perform all the relevant tests to be able to diagnose and appropriately treat anomalies of the accommodative system.

\section{References}

1. Francisco L, Pilar C, Angel G, Ramon M. General binocular disorders: prevalence in a clinic population. Ophthalmic Physiol Optics 200121 70-74.

2. Dzik D. Vision and the juvenile delinquent. J Am Optom Assoc 199637 461-8.

3. Banks MS. The development of visual accommodation during early infancy. Child Dev 198051 646-666.

4. Brookman KE. Ocular accommodation in human infants. Am J Optom Physiol Optics 198360 91-99.

5. American Academy of Pediatrics Committee on Practice and Ambulatory Medicine. Vision screening and eye examination in children. Pediatrics 198677 918-9.

6. Simons K. Preschool vision screening: rationale, methodology and outcome. Surv Ophthalmol 199641 3-30.

7. Borsting E. Rouse MW, Deland PN, Hovett S, Kimura D, Park M, Stephens B. Association of symptoms and convergence and accommodative insufficiency in school-age children. Optometry 200374 25-34.

8. Daum KM. Accommodative insufficiency. Am J Optom Physiol Optics 359198360352.

9. Cashell GTW, Durren IM. Handbook of Orthoptic Principles. 4th ed. Churchill Livingstone 1980.

10. Scheiman M, Wick B. Clinical Management of Binocular Vision. Philadelphia: JB Lippincott Company, 1994 pp 339378 .
11. Griffin JR, Grisham JD. Binocular Anomalies Diagnosis and Vision Therapy, 4th Edition. Butterworth Heinemann 2002 pp 41-49.

12. Ciuffreda KJ. Accommodation, the Pupil, and Presbyopia In: Borish's Clinical Refraction. Benjamin WJ, ed. Philadelphia: WB Saunders, 199892.

13. Marran LF, De Land PN, Nguyen AL. Accommodative insufficiency is the primary source of symptoms in children diagnosed with convergence insufficiency. Optom Vis Sci 200683 281-9.

14. Borish IM. Clinical refraction, 3rd ed. Chicargo: Professional Press;1975 169-170.

15. Duane A. Anomalies of accommodation clinically considered. TransAm Ophthalmol Soc 19151 386-400.

16. Constitution of the Republic of South Africa (Act 108 of 1996) pp.14-15.

17. Ayed T, Sokkah M, Charfi O, El Matri L. Epidemiologic study of refractive errors in schoolchildren in socioeconomically deprived regions in Tunisia. J Fr Ophtalmol 2002 25 712-7.

18. Gruning Carl F. Pre-school screenings: Are they enough? Optometric Management. July 2001 72-73.

19. Mabaso RG, Oduntan AO, Mpolokeng MBL. Refractive status of primary school children in Mopani district Limpopo Province, South Africa. S Afr Optom 200665 125-133.

20 Gordon A. Refractive error in Puerto Rican rural population. J Am Optom Assoc 199061 40-43.

21 Kalikivayi V, Naduvilath TJ, Bansal AK, Dandona L. Visual impairment in school children in Southern India. Indian J Ophthalmol 199745 129-134.

22 Pokharel GP, Negrel AD, Munoz SR, Ellwein LB. Refractive error study in children: results from Mechi Zone, Nepal. Am J Ophthalmol 2000129 436-444.

23. Goss D, Zhai H. Clinical and laboratory investigations of the relationship of accommodation and convergence function with refractive error. Documenta Ophthalmologica 199486 349-80.

24. Scheiman M, Herzberg H, Frantz K, Margolies M. Normative study of accommodative facility in elementary schoolchildren. Am J Optom Physiol Opt 198865 127-34.

25. Kedzia B, Pieczyrak D, Tondel G, Maples WC. Factors affecting the clinical testing of accommodative facility. Ophthalmic Physiol Opt 199919 12-21.

26. Lieberman S, Cohen A, Stolzberg M, Ritty JM. Validation study of the New York State Optometric Association (NYSOA) Vision Screening Battery. Am J Optom Physiol Opt 198562 165-8.

27. Scheiman M, Gallaway M, Coulter R, Reinstein F, Ciner E, Herzberg C, Parisi M. Prevalence of vision and ocular disease conditions in a clinical pediatric population. JAOA 199667 193-202.

28. Brutaset R, Wahlberg M, Abdi S, Pansell T. Accommodation insufficiency in children: are exercises better than reading glasses? Strabismus 200816 65-69.

29. Gruning Carl F. Clinical management of nearpoint stressinduced vision problems Am J Optom Physiol Opt 198562 386-391. 